\title{
Performance evaluation of Central European companies
}

\author{
Petr Fiala ${ }^{1, *}$ and Josef Jablonský ${ }^{1}$ \\ ${ }^{1}$ Department of Econometrics, University of Economics, Prague \\ W. Churchill Sq. 4, 13067 Praha 3, Czech Republic \\ E-mail: 〈\{pfiala, jablon\}@vse.cz〉
}

\begin{abstract}
The paper presents a modelling approach for performance comparison of Central European companies on three levels: country, industry, and company. The approach is based on Data Envelopment Analysis and Analytic Hierarchy Process. The proposed model consists of two basic sections. The first section estimates the importance of selected industries in the countries, whereas the second section evaluates the performance of companies within industries. The results of both sections are synthesized and finally the country performance is estimated. The evaluation is based on the data set resulting from a survey of companies from selected industries.
\end{abstract}

Key words: Data Envelopment Analysis, AHP, ANP, efficiency

Received: September 20, 2014; accepted: October 2, 2015; available online: October 31, 2015

DOI: $10.17535 /$ crorr.2015.0027

\section{Introduction}

The aim of the paper is to propose a methodological framework for evaluating performance and identifying performance gaps among selected Central European countries and highly developed industrial western European economies, and to try to identify the sources of inefficiencies in the evaluated units. The paper describes and discusses issues and results of the international project, while focusing on this subject of study.

There are several possible methodological approaches for evaluating company performance. The traditional approach relies solely on financial measures. Financial ratios provide relative comparisons of company performance over time and the ability to compare performance across different companies. Financial ratio analysis has been presented extensively in literature. The balanced scorecard was devised by Kaplan and Norton [5] as a performance measurement framework that added strategic non-financial performance measures to traditional financial metrics, thus providing managers and executives with a more 'balanced' view of organizational performance. Another

${ }^{*}$ Corresponding author. 
methodology is based on multi-criteria analysis of company performance. For example, Diakoulaki et al. [3] utilize the results of multi-criteria analysis, applied to a large sample of Greek pharmaceutical companies, in order to find out how suitable certain common financial ratios are as indices of a company's overall performance. Another proposed approach is based on Logarithmic Fuzzy Preference Programming (LFPP) and TOPSIS methods. The LFPP method is used to determine weights of criteria by decision makers and then company rankings are determined using the TOPSIS method [6].

The Analytic Hierarchy Process (AHP) is often used for evaluating alternatives. There are papers that focus on performance evaluation of companies using the AHP approach or a combination of other methods (e.g. [4], [12]). The novelty of our approach is the actual evaluation methodology of the hierarchical country-industry-company structure. The proposed multi-criteria approach starts with an evaluation of efficiency of companies selected from industries that are exceptionally important for countries in the study. Subsequently, the results from the first step are synthesized and industry efficiencies are derived. The last step consists of aggregating the results from the previous step based on the business strength of the country industries, and finally measures of relative country performance are derived. Due to the hierarchical nature of the process, the problem can be expressed as an AHP (and/or ANP) model.

The sub-models of this general approach evaluate the efficiency and performance of the most important industries and companies within the respective country industries. The questionnaire was conducted in 2013. To receive appropriate data sets for the evaluation, the questionnaire was prepared and distributed to hundreds of companies in the participating countries. Almost one thousand letters containing a questionnaire completion request were distributed in each of the participating countries (the Czech Republic, Poland, Hungary, Germany - divided into two parts - former East and West Germany, and further referenced as East and West Germany) to companies doing business in selected industries. For example, in the Czech Republic, 965 questionnaires were sent out and 142 completed questionnaires were returned, i.e., a return rate of $14.7 \%$. Even though the questionnaire return rate was quite low, sufficient number of data for a detailed analysis was collected (at least 20 companies from each industry in each country). Taken into account were the most important industries in the participating countries (construction, meat processing, furniture, freight, etc.). The industries were selected based on the number of companies in all countries, thus providing the opportunity to compare a sufficient number of equally sized samples from individual countries. 
The questionnaire in our survey had the following structure:

1. General company information

- Turnover,

- Pre-tax profit or loss,

- Fixed and variable costs,

- Estimated market share,

- Information on the basic features of the production process regarding the number of products or services, degree of automation in the production processes, share of intermediate consumption, etc.

2. Information related to company personnel and capital

- Personnel structure (management, administration, employees),

- Labor costs,

- Qualification of personnel and expenditure on improving qualifications,

- Floor space size of premises,

- Investments in fixed assets.

3. Information related to company management, organization and structure

- Number of hierarchies in the company's organizational structure,

- Main management roles and tasks.

4. Information related to production innovations and/or production processes

- Number of hierarchies in the company's organizational structure,

- Level of substantial changing or introduction of products/services,

- Expenditure on product/service innovations.

5. Information related to the company's networking activities

- Level of co-operation with customers and suppliers,

- Level and importance of current communication technologies (email, www, e-commerce).

The rest of the paper is organized as follows. The next section contains a brief description of the basic models used for evaluating performance based on a number of characteristics affecting efficiency. Section 3 describes an AHP model that derives efficiency scores for companies, industries and countries in the study and presents some results from the reduced data set. Application of this model using a real data set is described in Section 4. The last section contains a summary of results and a discussion concerning future research, i.e. a discussion on the possibilities of using analytic network processes to model the problem. 


\section{Methodological framework}

The process of analyzing country performance requires taking into account the performance of production units operating in the actual countries. Companies of significance in different industries are taken as the production units. Their performance depends on numerous factors that can be divided into two basic groups - inputs and outputs. Inputs are characterized as sources used by the company in the process of producing outputs. Next, a measure of company performance can be obtained by comparing outputs and inputs. It general holds that higher outputs and/or lower inputs lead to measures of higher performance. A knowledge of company performance measures can be used for estimating measures of industrial performance (based on the size of the companies in the survey and other factors). Similarly, the importance of the industries in the selected country together with measures of industrial performance provides an estimation of the measure of country performance.

One of the important problems arising from this process is performance evaluation of companies (efficiency, productivity) in regards to the information on their inputs and outputs that substantially influences performance. This study does not discuss selection of the main factors (inputs and outputs) for comparing performance but rather some of the basic models and techniques used in the evaluation. Clearly, the evaluation is based on a comparison of multiple inputs and outputs. Accordingly, one of the methodological tools for this is multiple criteria decision making.

Numerous multiple criteria decision-making methods are available which are usually based on computing utility measures of evaluated units by means weighing criteria. The most frequently used methods are WSA (Weighted Sum Approach), ELECTRE (ELimination Et Choix Traduisant la REalite) and PROMETHEE (Preference Ranking Organization METHod for Enrichment Evaluation) class methods, and the AHP (Analytic Hierarchy Process). AHP is not only a method for evaluating units but can also be advantageously used for hierarchical modeling of large, complex decision circumstances. Hence, it can be a suitable tool for our purposes. Our aim is not to describe in detail the mentioned methods. Further on, the brief characteristics of AHP, WSA and PROMETHEE II will be presented and those that are used most extensively in numerical experiments.

AHP is based on the ability of expressing a decision problem as a hierarchical structure. The hierarchy representing a decision problem always consists of several levels. The first topmost level defines the main goal of the decision problem, and the last lowest level usually describes the decision units. Between the first and the last level are secondary goals, criteria and subcriteria of the decision problem. The number of the levels is not limited, but it typically does not exceed four or five. The decision maker expresses the preferences or compares the importance of the elements at a given level with respect to an 
element at a preceding level. The information resulting from the decision maker's judgements at the given level of the hierarchy is synthesized into the local priorities. These can express, for instance, the relative importance of criteria or preference indices of units based on the given criterion. In the standard AHP model, the decision maker's judgements are organized into pairwise comparison matrices at each level of the hierarchy. The judgements are point estimates of a preference between two elements of a level. Let us denote the pairwise comparison matrix $\mathbf{A}=\left\{a_{i j} \mid a_{j i}=1 / a_{i j}, a_{i j}>0, i, j=1,2, \ldots, k\right\}$, where $k$ is the number of elements of a particular level. Saaty [8] proposes using $a_{i j}$ integers in the range of 1 to 9 , where 1 implies the $i$-th and the $j$-th elements that are equally important and 9 is the $i$-th element that is absolutely more important than the $j$ th element. The local priorities $v_{i}, i=1,2, \ldots, k$ are derived by solving the following eigenvector problem

$$
\begin{aligned}
& \mathbf{A . v}=\lambda_{\max } \mathbf{v}, \\
& \sum_{i=1}^{k} v_{i}=1,
\end{aligned}
$$

where $\lambda_{\max }$ is the largest eigenvalue of $\mathbf{A}$ and $\mathbf{v}$ is the normalized right eigenvector belonging to $\lambda_{\max }$.

The WSA method maximizes the weighted linear utility of evaluated units. The normalized criterion values are aggregated by means of weights and the utility of each evaluated unit is derived. The complete ranking of all the units is received by their global utilities.

The PROMETHEE II method operates with six basic types of preference functions. They are used for measuring the intensity of the preferences of all pairs of units (alternatives) based on the given criterion. The partial pairwise intensities are aggregated by means of criteria weights specified by the decision maker and global the preferences between pairs of units are derived. The complete ranking of all the units is obtained by their descending ordering according to their net flows computed from the global preferences.

Multiple criteria decision-making techniques are often based on defining the utility of units by means of several basic principles, e.g. aggregation of normalized criterion values. Another methodological framework that can be used for evaluating performance of decision-making units is Data Envelopment Analysis (DEA). The essential characteristic of the DEA model is the reduced number of multiple inputs and multiple outputs using weights computed by the model. This model searches for weights that define a virtual unit with the best (not worst) characteristics of the evaluated unit. This means that the virtual unit is the unit with lower and higher outputs compared to the evaluated unit. The unit is called efficient if no set of weights exist, that would otherwise define the virtual unit possessing the mentioned properties. Otherwise, the unit is not efficient and the virtual inputs and outputs are target values for reaching 
efficiency. The formulation of DEA models leads to a linear fractional programming problem that can be simply transformed into a standard linear programming problem.

\section{The AHP based model for performance evaluation}

Because of hierarchical structure of the above-discussed problem in evaluating performance of companies, industries and countries, we propose a simple twostep AHP model containing the following basic levels:

1. Countries. In our study, the countries of the former Eastern European block (the Czech Republic, Poland, Hungary and East Germany) on the one hand, and one highly developed Western country (West Germany) on the other hand, were included into this level. Generally, we could assume to have $h$ items (countries) on this level.

2. Industries. The most important industries for the mentioned region relating to goods and services are taken into account (machine building industry, meat processing, freight transport, construction, furniture, textiles, etc.). Let us denote $m$ to be the number of industries in the model.

3. Companies. A selection of the most important companies in the mentioned industries in all the countries was addressed by the questionnaire (its structure was presented in the introductory section of the paper) and the data from returned questionnaires were analyzed. We decided to consider an identical number of companies from all the industries and countries. This assumption is not essential and the model presented below can be easily modified for a different numbers of companies. Assuming an identical number of companies, the total number of companies in the study is $m . n$, where $n$ is the number of companies for all the countries belonging to an industry. This means that the number of companies belonging to an industry for a given country is $d=n / h$ (supposing we have $h$ countries).

4. Criteria influencing the company efficiency (inputs and outputs). The criteria used in the analysis corresponded to the questionnaire items. Given that the basic inputs can be considered fixed and variable costs, labor costs, available floor space, investments, etc., the output characteristics are turnover, profit, market share, etc. The total number of criteria $(r+s)$ consists of the number of inputs $(r)$ and the number of outputs $(s)$.

5. Criteria influencing the position of the industries within the countries (e.g. GNP, employment, tradition of the industry in the country, etc.). The number of elements at this level is $t$. 


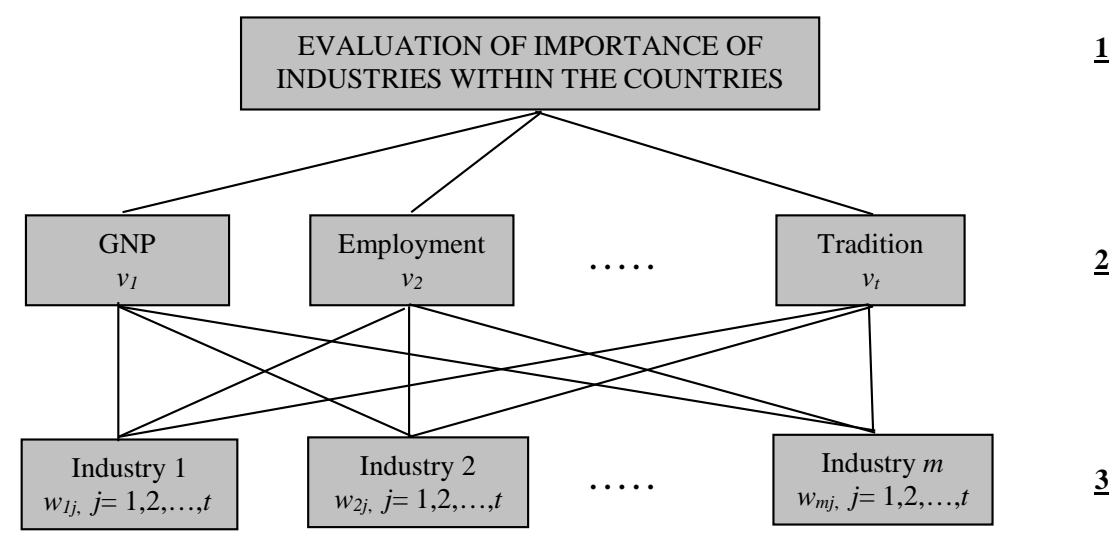

Figure 1: First step - evaluating the importance of industries in countries.

The proposed AHP model contains the following three steps:

\section{Estimation of the relative strength of the industries in countries.}

The AHP model presented in Figure 1 is applied for each country. It is the standard three-level AHP model with criteria used to evaluate the units (industries) that influence their strength. The results of this model are assigned to the $i$-th industry and have relative importance in the $k$-th country expressed by $p_{i k}, i=1,2, \ldots, m, k=1,2, \ldots, h$,

$$
p_{i k}=\sum_{j=1}^{t} w_{i j}, i=1,2, \ldots, m, k=1,2, \ldots, h, \sum_{i=1}^{m} w_{i j}=v_{j}, j=1,2, \ldots, t, \sum_{j=1}^{t} v_{j}=1 .
$$

\section{Evaluation of performance of companies within industries.}

The hierarchical model for this step is presented in Figure 2. The model is solved for all industries separately, which means having to analyze $m$ similar AHP models. The result of each of these models is that we have

$$
q_{i k}=\sum_{j=1}^{r+s} u_{i j}, i=1,2, \ldots, n, k=1,2, \ldots, m
$$

where $q_{i k}$ values express the relative performance of the $i$-th company belonging to the $k$-th industry. Due to the principle of dividing up preferences from the higher hierarchical level to the lower level, the sum of $q_{i k}$ values across all companies $i=1,2, \ldots, n$ is equal to unity for all industries $k=1,2, \ldots, m$.

\section{A synthesis of the results from the previous two steps.}

The efficiency score for the countries is derived from the results of the previous two steps. Let us denote the efficiency score for the $k$-th country as $P_{k}$, $k=1,2, \ldots, h$. It can be given as follows: 


$$
P_{k}=\sum_{j \in C_{k}} \sum_{i=1}^{m} p_{i k} q_{j i}, \quad k=1,2, \ldots, h,
$$

where $C_{k}$ is the set of indices of companies in the $k$-th country. The set of indices of companies within any industry is $\{1,2, \ldots, n\}$. We use the following splitting: $\quad C_{1}=\{1,2, \ldots, d\}, \quad C_{2}=\{d+1, d+2, \ldots, 2 d\}, \ldots, \quad C_{h}=\{n-d+1$, $n-d+2, \ldots, n\}$. Due to the above relations, the sum of $P_{k}$ across all countries equals unity.

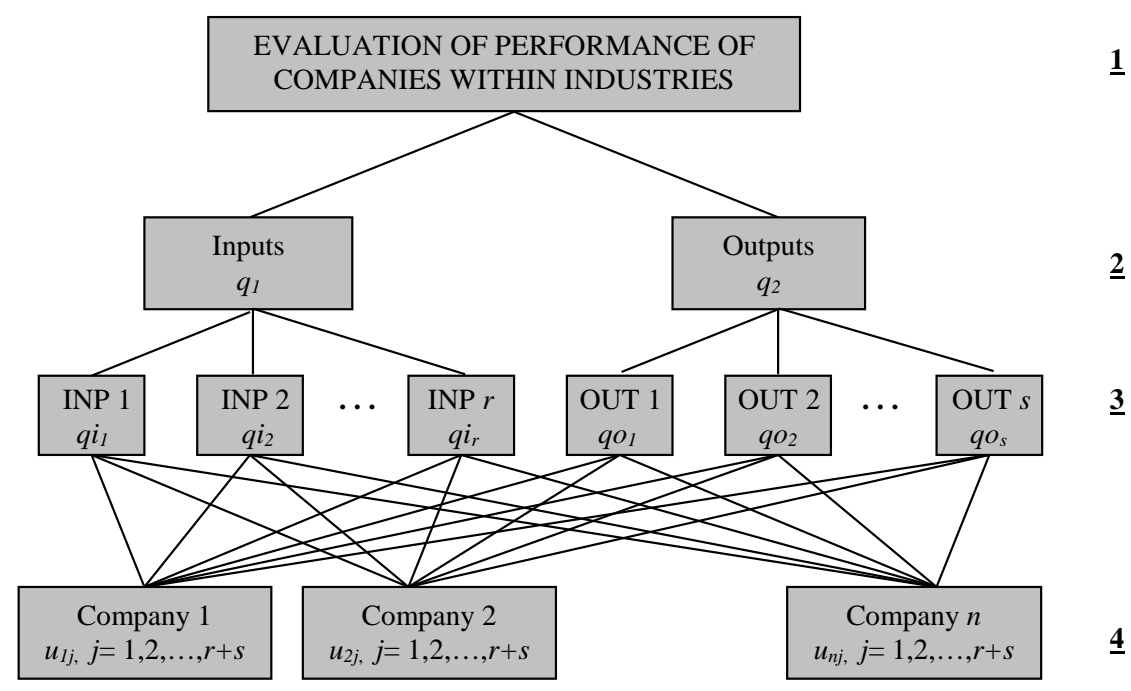

Figure 2: Second step - evaluation of performance of companies.

\section{An illustrative case}

The presented approach will be illustrated on a small example covering 5 countries (the Czech Republic (CZ), Poland (PL), Hungary (HU), East (GE) and West (GW) Germany), 3 industries (construction, meat processing and freight transport) and 2 companies in each of the industries and countries, i.e. the total number of companies in this example is 30. All the companies are described by 4 inputs (fixed costs, number of employees, floor space and investments) and 2 outputs (turnover and market share). The inputs and outputs characterizing all the companies are presented in Table 1 . The results of the AHP model presented in the previous section of the paper will be compared to the DEA analysis and results of the WSA and PROMETHEE II methods. 


\begin{tabular}{|c|c|c|c|c|c|c|c|}
\hline $\begin{array}{l}\text { Industry/ } \\
\text { Company }\end{array}$ & Country & $\begin{array}{l}\text { Fixed } \\
\text { costs }\end{array}$ & $\begin{array}{c}\text { \# of } \\
\text { workers }\end{array}$ & $\begin{array}{l}\text { Floor } \\
\text { space }\end{array}$ & Investments & Turnover & $\begin{array}{c}\text { Market } \\
\text { Share }\end{array}$ \\
\hline & & mil. $€$ & $\#$ & sq. $m$ & mil. $€$ & mil. $€$ & $\%$ \\
\hline \multicolumn{2}{|c|}{ Weights of inputs/outputs } & 0.3368 & 0.14181 & 0.0612 & 0.0830 & 0.2973 & 0.0799 \\
\hline Construction/1 & $\mathrm{CZ}$ & 11.743 & 164 & 6600 & 0.171 & 12.314 & 55 \\
\hline Construction/2 & $\mathrm{CZ}$ & 2.257 & 308 & 10000 & 0.486 & 11.571 & 10 \\
\hline Meat/1 & $\mathrm{CZ}$ & 5.468 & 458 & 20129 & 0.010 & 12.943 & 10 \\
\hline Meat/2 & $\mathrm{CZ}$ & 3.657 & 316 & 27000 & 0.914 & 6.229 & 80 \\
\hline Transport/1 & $\mathrm{CZ}$ & 9.143 & 80 & 5000 & 0.600 & 14.543 & 10 \\
\hline Transport/2 & $\mathrm{CZ}$ & 5.743 & 421 & 18652 & 0.286 & 16.029 & 10 \\
\hline Construction/1 & $\mathrm{PL}$ & 2.251 & 37 & 8537 & 0.184 & 9.043 & 2 \\
\hline Construction/2 & PL & 0.285 & 85 & 29400 & 0.284 & 6.599 & 80 \\
\hline Meat/1 & PL & 1.000 & 100 & 3000 & 0.168 & 13.233 & 100 \\
\hline Meat/2 & PL & 1.611 & 95 & 3000 & 0.057 & 3.771 & 10 \\
\hline Transport/1 & PL & 2.281 & 366 & 18848 & 0.258 & 15.288 & 2 \\
\hline Transport/2 & $\mathrm{PL}$ & 3.544 & 235 & 24000 & 0.204 & 5.724 & 5 \\
\hline Construction/1 & $\mathrm{HU}$ & 2.789 & 49 & 1101 & 0.974 & 30.567 & 2 \\
\hline Construction/2 & $\mathrm{HU}$ & 1.800 & 198 & 2500 & 0.818 & 22.362 & 18 \\
\hline Meat/1 & $\mathrm{HU}$ & 3.047 & 559 & 40000 & 2.493 & 21.817 & 3 \\
\hline Meat/2 & $\mathrm{HU}$ & 2.376 & 74 & 4385 & 0.074 & 2.645 & 80 \\
\hline Transport/1 & $\mathrm{HU}$ & 1.886 & 316 & 14300 & 1.800 & 13.800 & 5 \\
\hline Transport/2 & $\mathrm{HU}$ & 1.000 & 79 & 45000 & 0.010 & 8.114 & 60 \\
\hline Construction/1 & GW & 12.271 & 220 & 11000 & 1.534 & 86.920 & 40 \\
\hline Construction/2 & GW & 1.790 & 78 & 1200 & 0.041 & 17.282 & 15 \\
\hline Meat/1 & GW & 7.005 & 85 & 22000 & 0.562 & 16.873 & 30 \\
\hline Meat/2 & GW & 0.665 & 75 & 5600 & 0.153 & 11.248 & 5 \\
\hline Transport/1 & GW & 6.136 & 80 & 3500 & 0.511 & 13.294 & 10 \\
\hline Transport/2 & GW & 0.782 & 57 & 1400 & 0.818 & 8.896 & 20 \\
\hline Construction/1 & $\mathrm{GE}$ & 1.023 & 62 & 1500 & 0.015 & 3.272 & 20 \\
\hline Construction/2 & GE & 1.841 & 111 & 2900 & 0.010 & 5.317 & 35 \\
\hline Meat/1 & GE & 6.382 & 88 & 21000 & 0.662 & 12.976 & 20 \\
\hline Meat/2 & GE & 4.244 & 77 & 19000 & 3.375 & 31.189 & 30 \\
\hline Transport/1 & GE & 4.286 & 65 & 1600 & 0.162 & 4.421 & 30 \\
\hline Transport/2 & GE & 2.301 & 132 & 5900 & 3.630 & 11.862 & 40 \\
\hline
\end{tabular}

Table 1: Input and output characteristics of the companies.

First step of the proposed approach is to evaluate the importance of industries in the countries. For each of the five countries, the model shown in Figure 1 containing 3 criteria (GNP, employment, tradition) and 3 industries was applied and an expert was asked to make pairwise comparisons in the model. The results $\left(p_{i k}, i=1,2,3, k=1,2, \ldots, 5\right)$ are summarized in Table 2 .

\begin{tabular}{|c|c|c|c|c|c|}
\hline & CZ & PL & HU & GW & GE \\
\hline Building & 0.425 & 0.508 & 0.343 & 0.447 & 0.447 \\
\hline Meat processing & 0.212 & 0.242 & 0.442 & 0.191 & 0.191 \\
\hline Transport & 0.363 & 0.250 & 0.215 & 0.352 & 0.352 \\
\hline
\end{tabular}

Table 2: National importance coefficients for industries. 
The second step involves computing the performance scores for all the companies within their industries using the model presented on Figure 2. The weights of the inputs and outputs derived by their pairwise comparisons are listed in the second row of Table 1 . These values are used for computing the performance scores of companies $q_{i k}, i=1,2, \ldots, 10, k=1,2,3$ in Table 3 . Due to the limited discussion in the paper, we will not be presenting pairwise comparison matrices for derived $u_{i j}$ values. The values $q_{i k}, i=1,2, \ldots, 10$, $k=1,2,3$ in Table 3 express the relative performance of the companies belonging to one of the selected industries. It is noticeable that the most efficient building companies is the second Polish company, whereas the worst are both Czech companies. Similar conclusions can be drawn from the other columns of the table below (meat processing and freight transport):

\begin{tabular}{|c|c|c|c|}
\hline & Construction & Meat processing & Transport \\
\hline CZ1 & 0.06038 & 0.05839 & 0.07977 \\
\hline CZ2 & 0.05753 & 0.05904 & 0.07770 \\
\hline PL1 & 0.08527 & 0.15543 & 0.08517 \\
\hline PL2 & 0.15189 & 0.09211 & 0.05227 \\
\hline HU1 & 0.11389 & 0.07912 & 0.10182 \\
\hline HU2 & 0.09178 & 0.10589 & 0.16178 \\
\hline GW1 & 0.11803 & 0.08534 & 0.08972 \\
\hline GW2 & 0.11382 & 0.16481 & 0.16562 \\
\hline GE1 & 0.11814 & 0.06439 & 0.09490 \\
\hline GE2 & 0.08928 & 0.13547 & 0.09124 \\
\hline
\end{tabular}

Table 3: Performance of the companies.

The results in Table 3 can be synthesized using weights of industries in Table 2. The final results are presented in the first column of Table 4. The AHP model shows that West German companies achieve the highest performance, whereas the Czech companies achieve lower performance. Excluding the results given by the AHP model, Table 4 contains the average performance scores of the countries computed using other approaches - DEA (CCR input-oriented model), WSA and PROMETHEE II. All the results were standardized to the sum of unity. By comparing all the results, it is evident that the results provided by the AHP model are very close to the DEA model, which is a special technique for evaluating efficiency of a set of homogenous production units. The same holds true for the other used methods, even though there are some reversals in country ranking. Of course, general conclusions cannot be drawn due to the small number of companies taken into account and the illustrative character of the numerical example (even it is based on a real data set). 


\begin{tabular}{|c|c|c|c|c|}
\hline & AHP & DEA & WSA & PROM \\
\hline CZ & 0.13217 & 0.12419 & 0.15532 & 0.14959 \\
\hline PL & 0.21474 & 0.20700 & 0.22017 & 0.19244 \\
\hline HU & 0.20899 & 0.21585 & 0.20483 & 0.23229 \\
\hline GW & 0.24130 & 0.23245 & 0.21123 & 0.23249 \\
\hline GE & 0.19641 & 0.22051 & 0.20845 & 0.19319 \\
\hline
\end{tabular}

Table 4: Performance scores of the countries.

The generalized model for measuring performance in Central European countries is based on the Analytic Network Process (ANP) approach [9]. The ANP approach is measuring the local performance of units and for comparing their global performance as well. The structure of the ANP model is described by clusters of elements connected by their dependence on one another. A cluster contains elements that share a set of attributes [9]. At least one element in each of these clusters is connected to some element in another cluster. These connections indicate the flow of influence between the elements.

Pairwise comparisons are needed for all the connections in the performance model - as they are considered as inputs for computing the global performance of network production systems. A supermatrix is a matrix of all elements by all elements. The weights from the pairwise comparisons are placed in the appropriate column of the supermatrix. The sum of each column corresponds to the number of comparison sets. The weights in the column corresponding to the cluster are multiplied by the weight of the cluster. Each column of the weighted supermatrix sums to one and the matrix is column stochastic. Its powers stabilize after several iterations to a limited supermatrix. The columns of each block of the matrix are identical and we can read off the global priority of the business units.

In the generalized model, we take into account countries, industries, companies and criteria as clusters and different types of connections in the system. There are some dependencies and feedback among elements and clusters also. The whole system is more properly represented as network system. We state some examples of dependencies in the system. There are dependencies among countries given by foreign trade. The industries are interconnected and the flows can be modelled by input-output models. The questionnaire contains questions on the networking activities of companies as rates of co-operation with customers and suppliers. The dependencies and feedback should be expressed by appropriate measures.

We used the ANP software Super Decisions developed by Creative Decisions Foundation (CDF) for some experiments by testing the possibilities of the expression and evaluating performance of the network system (Figure 3). Figure 3 contains an example of 4 clusters of our performance evaluation model 
and basic dependencies among them. It presents an introductory idea for the ANP performance evaluation model only.

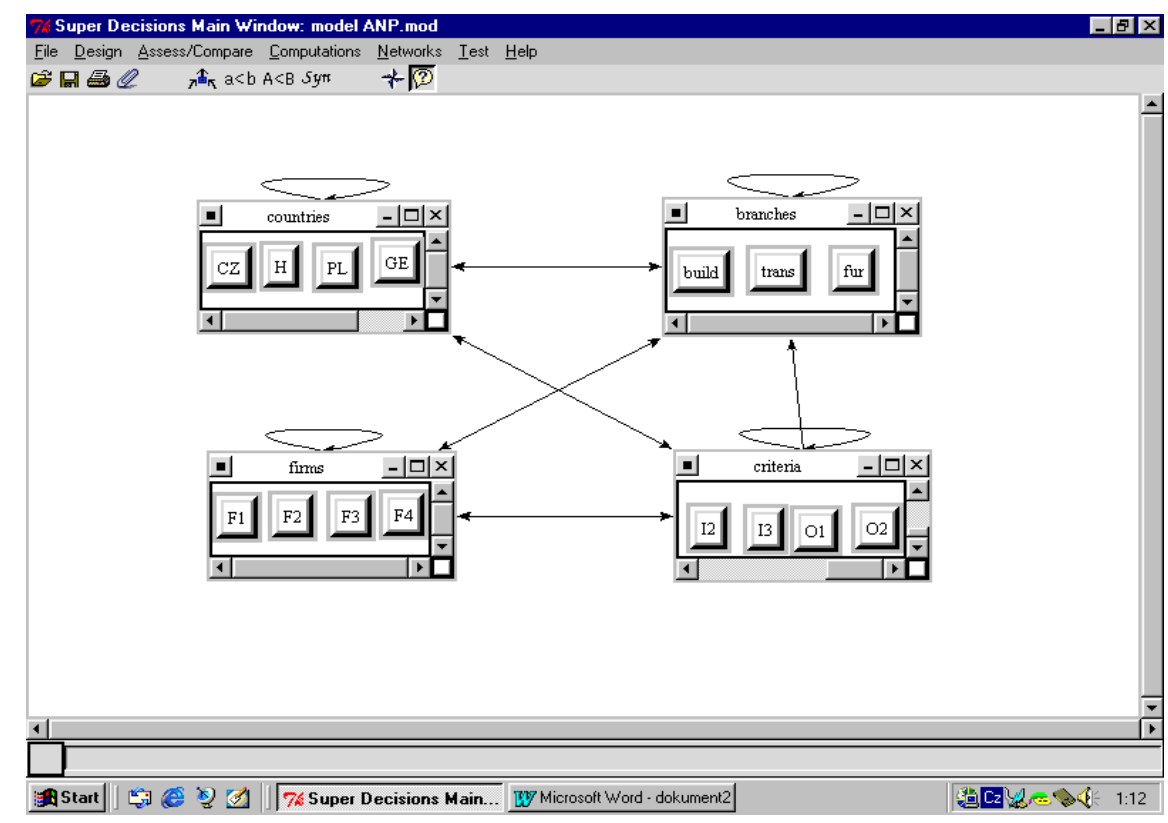

Figure 3: Generalized ANP model.

\section{Conclusions}

Performance models help to understand the behaviour of business systems and provide guidelines for improving their performance. The AHP model presented in this paper offers a simple approach to estimating performance scores of countries, industries and companies as well. The main contribution that this paper provides is in developing an evaluation methodology of a hierarchical structure depicting country-industry-company. We have proposed the a generalized model based on the ANP. The ANP approach seems to be better suited for performance analysis than the standard AHP models, as it enables the modelling of dependencies among basic elements of the model that otherwise affect performance. In the proposed model, there are strong linkages and feedbacks among countries, industries and performance criteria. These relations are important between pairs of clusters on one side, and among elements of clusters on the other side. The possibility of using qualitative and difficult to measure characteristics is its advantage as opposed to other techniques. The basic principle of the approach is illustrated on a small example. Consequently, the results cannot be generalized due to the difficult in identifying sources of inefficiencies in the sample. One of the major sources of inefficiency may be 
insufficient utilization of network activities, but the questionnaires did not contain sufficient information for comparison purposes. A large study taking into account a large number of companies from numerous industries is under preparation and will be the aim of our future research. This future research will be oriented towards combining new versions of ANP and DEA approaches. These approaches are being developed to capture the network and dynamic properties of performance evaluations. Individual units are interconnected in a network system by material, financial and information flows. The network system is responsible for global performance, whereas each unit is responsible for local performance. The ANP approach seems to be an appropriate method for measuring the performance of network production systems, but there is a dynamic version of ANP [10] as well and it is also possible extending DEA to network version (e.g. [1]). In DEA, there are several methods for measuring efficiency change over time (e.g. [7], [11]). Therefore, future research will be oriented toward more detailed and sophisticated network models and a methodology for measuring the dynamic performance of network systems.

\section{Acknowledgements}

The research is supported by the Grant Agency of the Czech Republic, projects no. 13-07350S and no. P403/12/1387.

\section{References}

[1] Chen, C. M. (2009). A network-DEA model with new efficiency measures to incorporate the dynamic effect in production networks. European Journal of Operational Research, 194(3), 687-699. doi:10.1016/j.ejor.2007.12.025.

[2] Cooper, W. W., Seiford, L. M. and Tone, K. (2000). Data Envelopment Analysis. Boston: Kluwer Publ.

[3] Diakoulaki, D., Mavrotas, G. and Papayannakis, L. (1992). A multicriteria approach for evaluating the performance of industrial firms. Omega, 20(4), 467-474. doi:10.1016/0305-0483(92)90021-X.

[4] Ertuğrul, I. and Karakaşoğlu, N. (2009). Performance evaluation of Turkish cement firms with fuzzy analytic hierarchy process and TOPSIS methods. Expert Systems with Applications, 36(1), 702-715. doi:10.1016/j.eswa.2007.10.014.

[5] Kaplan, R. S. and Norton, D. P. (1992). The balanced scorecard: Measures that drive performance. Harvard Business Review, 70(1), 71-79.

[6] Moradi, M. and Janatifar, H. (2014). Performance evaluation of automobile companies based on multi-criteria decision making techniques. Global Journal of Management Studies and Researches, 1(2), 77-84.

[7] Nemoto, J. and Goto, M. (1999). Dynamic Data Envelopment Analysis: Modeling intertemporal behavior of a firm in the presence of productive inefficiencies. Economic Letters, 64(1), 51-56. doi:10.1016/S0165-1765(99)00070-1. 
[8] Saaty, T. L. (1990). The Analytic Hierarchy Process. Pittsburgh: RWS Publications.

[9] Saaty, T. L. (1996). Decision Making with Dependence and Feedback: The Analytic Network Process. Pittsburgh: RWS Publications.

[10] Saaty, T. L. (2007). Time dependent decision making; dynamic priorities in the AHP/ANP: Generalizing from points to functions and from real to complex variables. Mathematical and Computer Modeling, 46(7-8), 860-891. doi:10.1016/j.mcm.2007.03.028.

[11] Tone, K. and Tsutsui, M. (2010). Dynamic DEA: A slacks-based measure approach. Omega, 38(3-4), 145-156. doi:10.1016/j.omega.2009.07.003.

[12] Yurdakul, M. and İç, Y. T. (2004). AHP approach in the credit evaluation of the manufacturing firms in Turkey. International Journal of Production Economics, 88(3), 269-289. doi:10.1016/S0925-5273(03)00189-0. 